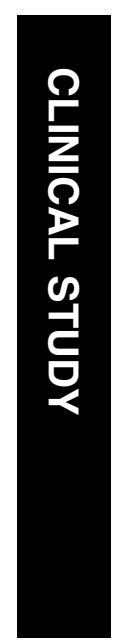

Interventions for relieving pain associated with panretinal photocoagulation: a prospective randomized trial

${ }^{1}$ Department of Ophthalmology, Chang Gung Memorial Hospital, Taoyuan, Taiwan

${ }^{2}$ The Department of Business Administration, Chang Gung University, Taoyuan, Taiwan

Correspondence: C-C Lai, Department of Ophthalmology, Chang Gung Memorial Hospital, 5 Fu-Hsin St, Kwei-Shan, 333, Taoyuan,

Taiwan

Tel: + 88633281200 ext 8666;

Fax: + 88633287798 .

E-mail: ccl404@

adm.cgmh.org.tw

Received: 26 April 2005 Accepted: 18 May 2005 Published online: 8 July 2005

None of the authors has any commercial or financial interests or conflicting relationships in respect to any products referred to in this article.

\section{The paper has been} presented in part at the Taiwan Academy of Ophthalmology Annual Meeting, October 2004, Taipei, Taiwan.

\section{Abstract}

Purpose To evaluate the efficacy of pain relief by oral diazepam, acetaminophen, mefenamic acid, intramuscular ketorolac tromethamine, and peribulbar anaesthesia in panretinal photocoagulation (PRP).

Methods A total of 220 patients with proliferative diabetic retinopathy requiring PRP treatment were enrolled in this study. Before laser treatment, the patients were allocated randomly to one of eight groups: group 1: diazepam $(n=22)$, group 2: acetaminophen $(n=21)$, group 3: mefenamic acid $(n=21)$, group 4 : diazepam and acetaminophen $(n=22)$, group 5 : diazepam and mefenamic acid $(n=22)$, group 6: peribulbar anaesthesia with lidocaine $(n=23)$, group 7: intramuscular injection of ketorolac tromethamine $(n=22)$, group 8: placebo $(n=67)$. Pain after the laser treatment was assessed by a verbal descriptive scale. Blood pressure and heart rate were measured before and after laser treatment.

Results Patients receiving peribulbar anaesthesia had a significantly lower pain score than the control group $(P<0.0001)$. Additionally, the peribulbar anaesthesiatreated group had the significantly least PRP-associated rise in either systolic $(P=0.043)$ or diastolic blood pressure rates $(P=\mathbf{0 . 0 3 0})$. There were no significant differences in pain score using other anesthetic agents when compared with the control group. There were no significant changes in heart rate after PRP treatment. Conclusion Peribulbar anaesthesia is effective in reducing pain and blood pressure increase after PRP treatment. Oral diazepam,
W-C Wu' ${ }^{1}$ K-H Hsu'2, T-L Chen¹, Y-S Hwang1, K-K Lin'1, L-M Li', C-P Shih² and C-C Lai ${ }^{1}$ mefenamic acid, and acetaminophen (either alone or in combination with each other) are not effective in preventing PRP treatmentassociated pain. Intramuscular injection of ketorolac tromethamine is also not effective in reducing PRP-associated pain.

Eye (2006) 20, 712-719. doi:10.1038/sj.eye.6701989; published online 8 July 2005

Keywords: peribulbar anesthesia; pain; panretinal photocoagulation

Introduction

Panretinal photocoagulation (PRP) is an effective treatment in reducing severe visual loss in patients with proliferative diabetic retinopathy (PDR). ${ }^{1-4}$ The Diabetic Retinopathy Study (DRS) recommended that treatment consists of 800-1600 argon laser burns of $500 \mu \mathrm{m}$ size to the peripheral retina in a scatter fashion. ${ }^{1}$ However, previous studies have shown that PRP is a painful procedure for most patients. ${ }^{5-7}$ Therefore, to reduce patient suffering during PRP, some pain-reliving procedures are necessary when performing PRP.

There are several options to reduce pain associated with PRP performed on an outpatient basis. Retrobulbar anaesthesia, peribulbar anaesthesia, and subtenon anaesthesia are effective pain-relieving procedures, but are invasive for patients with potential complications. ${ }^{8-11}$ Transcutaneous electrical nerve stimulation has been advocated in the practice of PRP, but special instrumentation is required. Additionally, the optimal setting of this treatment for ocular pain remains to be determined. ${ }^{12}$ Oral or intramuscular administration of anesthetic 
agents is generally considered as a safe means of drug delivery with almost no ocular complications. To the best of our knowledge, the role of oral or intramuscular painreliving agents in PRP has not been previously explored. Only a few published studies have examined the various anesthetic agents or techniques. ${ }^{5-7,12-14}$

Therefore, in this prospective study, we study whether some commonly used oral or intramuscular anesthetic agents are as effective in reducing pain accompanying PRP treatment as peribulbar anaesthesia. The purpose of this study is to reveal safer, noninvasive alternatives for pain control in patients receiving PRP treatment. Pain ratings by the patients, blood pressure, and pulse were documented as subjective and objective indicators related to pain. Blood pressure and pulse responses to the pain stimulus, while not indicative of pain-specific responses, were included as indicators of general body arousal. ${ }^{15}$ It was predicted that effective interventions would result in lower ratings of pain and decreased physiological reactivity relative to control subjects.

\section{Patients and methods}

\section{Subjects}

A prospective, randomized, study was performed to evaluate the efficacy of various anesthetic agents during PRP treatment. The study was conducted in Chang Gung Memorial Hospital after institutional review board approval was obtained. The patient records were collected consecutively from April 2002 to May 2004. All patients gave informed consent. Patients with PDR, requiring PRP treatment as evidenced on fundus examination and fluorescein angiography, were included. Patients with following conditions were excluded: PDR with concomitant neovascular glaucoma, end-stage renal disease, abnormal liver function, poor control of hypertension, patients with previous laser therapy, and patients with PDR combined with vitreous haemorrhage requiring use of krypton red laser. Only one eye per person was included in the study. Patients' demographic data, diabetes mellitus (DM) type, duration of DM, present medications, and presence of other systemic diseases (hypertension, asthma, renal disease, and neuropathy) were recorded. The sample size of each group in this study was calculated as 18 , with a significance level $\leq 0.05$ and a statistical power $=0.8$. The standard deviation of changes in systolic pressure was 23 in this study.

\section{Randomization and drug delivery}

Allocation sequence was generated from random number tables and concealed in sequentially numbered, opaque, sealed envelopes until the patients were randomized in a $1: 1: 1: 1: 1: 1: 1: 3$ ratio to one of eight groups: group 1 received an oral intake of $5 \mathrm{mg}$ diazepam (Valium, Roche, Basel, Switzerland); group 2 received an oral intake of $500 \mathrm{mg}$ acetaminophen (Tylenol, McNeil Consumer and Specialty Pharmaceuticals, Ft

Washington, PA, USA); group 3 received an oral intake of $500 \mathrm{mg}$ mefenamic acid (Mefic, Pfizer, New South Wales, Australia); group 4 received $5 \mathrm{mg}$ diazepam and $500 \mathrm{mg}$ acetaminophen orally; group 5 received $5 \mathrm{mg}$ diazepam and $500 \mathrm{mg}$ mefenamic acid orally; group 6 received $4 \mathrm{ml}$ of peribulbar anaesthesia with $2 \%$ lidocaine (Xylocaine, AstraZeneca AB, Södertälje, Sweden); group 7 received intramuscular injection of $30 \mathrm{mg}$ ketorolac tromethamine (Torado, Roche Laboratories Inc., Nutley, NJ, USA); and group 8 received no treatment as the control group. One of the authors was responsible for the drug administration to the patients. Medications were given at various time points before PRP treatment to achieve maximal effect of the anesthetic agents according to the manufacturers' recommendations. Timing of administration was as follows: oral drugs were given $2 \mathrm{~h}$ before PRP; peribulbar anaesthesia was performed half an hour before PRP; and intramuscular injection was performed $1 \mathrm{~h}$ before PRP.

The procedure of peribulbar anaesthesia was according to the previous published recommendation with modifications. ${ }^{16}$ In brief, peribulbar anaesthesia was performed using $2 \%$ lidocaine. This was injected through the lower eyelid immediately above the orbital rim at the juncture of the medial two-thirds and lateral third parallel to the orbital floor, and through the upper eyelid immediately below the upper eyelid at the juncture of the medial third and lateral two-thirds parallel to the orbital roof. The puncture was performed with a 25-gauge, 25-mm needle introduced completely through the skin. The patient was then asked to move his eyes horizontally to make sure that no ocular perforation occurred. Lidocaine, $2 \mathrm{ml}$, was used for each injection. The procedure was performed with the eye in the primary position, followed by 10-15 min of ocular compression. Adverse effects after drug administration were recorded. If a patient was found to be allergic to the administered medication, then the patient was given adequate treatment and dropped from this study. If the patient was unable to tolerate the pain during PRP, then retrobulbar anaesthesia was performed. These patients were subsequently dropped from this study.

\section{Laser application}

The pupils of patients in this study were dilated with $1 \%$ tropicamide (1\% mydriacyl, Alcon Laboratories, Hempstead, UK) after the administration of the analgesic 
agents. After topical application of hydrochloride (Novesin, Novartis, Hettlingen, Switzerland), the patients were instructed to sit before an argon green laser machine (Novus Omni, Coherent, Polo Alto, CA, USA) with a laser setting of wavelength $521 \mathrm{~nm}$, spots size $500 \mu \mathrm{m}$, and exposure time $0.2 \mathrm{~s}$. Repetitive mode ' $\mathrm{D}$ ' was chosen for laser delivery through a fundus contact lens (QuadrAspheric, Volk, Mentor, OH, USA). Laser energy was adjusted to achieve moderate whitening in the retina. Burns were placed approximately one burn-width apart. Treatment guidelines were according to guidelines from the DRS. ${ }^{1}$ The inferior retina was treated first. The first, the third, and the last researchers, who performed laser treatments in the patients, were not masked to the treatments the patients received. The patients were not masked either.

\section{Examinations}

Before laser treatment, visual acuity and intraocular pressure were checked in each patient. Pain sensation was evaluated immediately after treatment by the sixth researcher with a verbal rating scale, ${ }^{17}$ which had been found to be a useful clinical pain index of pain intensity among postoperative patients. ${ }^{18}$ The verbal scale included a range from 0 (no pain at all), 1 (slight discomfort), 2 (mild pain), 3 (moderate pain), 4 (severe pain), to 5 (extremely painful).

Blood pressure and heart rate were taken by a digital blood pressure monitor (ES-P350, Terumo, Tokyo, Japan) $15 \mathrm{~min}$ before and immediately after laser treatment. Before laser treatment, measurements were obtained after the patients had rested for at least $15 \mathrm{~min}$; the mean of three measurements obtained during a $15-$ min period was recorded.

\section{Statistics}

The variables described were expressed as mean and standard deviation. Patients' demographic data among groups were compared using chi-square test or Fisher's exact test when applicable. Paired $t$ test was used to compare changes in blood pressure and pulse rate before and after PRP treatment. Analysis of variance (ANOVA) was performed to compare laser parameters between each group. If statistical significance was reached by ANOVA, then Dunnett test was used to compare the difference with the control group. Blood pressure changes, pulse changes, and pain score among the different treatment groups were compared with regression models adjusting the demographic variables and laser treatment parameters. Statistical computations were performed using SAS 8.2 (SAS Institute Inc., Cary,
NC, USA). Statistical significance was accepted for $P$ values smaller than 0.05 .

\section{Results}

The study enrolled 223 patients. Three patients were dropped out of the study due to intolerable pain during laser treatment, and finished laser treatment after receiving retrobulbar anaesthesia injection. The remaining patients' distribution and the demographic data are detailed in Table 1. Among these groups, there were no statistical differences in the distribution of sex, age, DM, hypertension, asthma, and peripheral neuropathy. However, there were significantly more patients with heart disease $(P=0.004)$, renal disease $(P=0.002)$, and history of drug hypersensitivity $(P=0.009)$ in the control group.

Laser parameters delivered to the patients are given in Table 2. There was no statistical difference in the spot number delivered to the patients in each group. The mean number of laser treatments delivered to the patients was $450.88 \pm 109.48$. There was no significant difference in laser energy delivered to each group, except in the ketorolac tromethamine treatment group. Laser energy used in the ketorolac tromethamine treatment group was significantly less than that in the control group $(248.07 \pm 45.71 \mathrm{~mW}$ vs $313.65 \pm 96.96 \mathrm{~mW}$, $P=0.006)$.

Most of the patients reported painful sensation when undergoing PRP treatment. In the control group, 49 of 67 patients $(73 \%)$ experienced moderate or greater pain, indicating PRP is truly a painful procedure for most patients. Only the peribulbar injection group had a statistically significant difference in pain score when compared with the control group $(0.83 \pm 1.27$ vs $3.02 \pm 1.02, P<0.0001)$.

The results of blood pressure, pulse rate, and pain score before and after laser treatment are summarized in Table 3. After laser treatment, systemic blood pressure increased significantly in all groups of patients. The average increase in systolic pressure in the control group was $27.71 \pm 23.26 \mathrm{mmHg}$ after PRP treatment. The lidocaine-treated group $(16.51 \pm 20.44 \mathrm{mmHg})$ had the least increase in systolic pressure among all the groups. Compared with the control group, the difference reached statistical significance $(P=0.043)$.

Similarly, diastolic pressure increased significantly in all group of patients after laser treatment, except for the lidocaine group. The average increase in diastolic pressure in the control group was $15.01 \pm 13.94 \mathrm{mmHg}$, while only an increase of $4.77 \pm 13.33 \mathrm{mmHg}$ was noted in the lidocaine-treated group. The lidocaine-treated group was the only group that was significantly different from the control group with regard to the increase in 
Table 1 Demographics of study patients

\begin{tabular}{|c|c|c|c|c|c|c|c|c|c|}
\hline \multirow[t]{2}{*}{ No. of patients } & Group 1 & Group 2 & Group 3 & Group 4 & Group 5 & Group 6 & Group 7 & Group 8 & $P$-value \\
\hline & 22 & 21 & 21 & 22 & 22 & 23 & 22 & 67 & - \\
\hline \multicolumn{10}{|l|}{ Sex, no. $(\%)$} \\
\hline Male & $10(45)$ & $10(48)$ & $11(52)$ & $9(41)$ & $10(45)$ & $7(30)$ & $11(50)$ & $32(48)$ & 0.699 \\
\hline Female & $12(55)$ & $11(52)$ & $10(48)$ & $13(59)$ & $12(55)$ & $16(70)$ & $11(50)$ & $35(52)$ & \\
\hline \multicolumn{10}{|l|}{ Age, no. (\%) } \\
\hline$<55 y$ & $7(32)$ & $4(19)$ & $8(38)$ & $6(27)$ & $8(36)$ & $6(26)$ & $14(64)$ & $27(40)$ & 0.301 \\
\hline $55-65 y$ & $7(32)$ & $7(33)$ & $7(33)$ & $7(32)$ & $7(32)$ & $11(48)$ & $4(18)$ & $22(33)$ & \\
\hline$>65 y$ & $8(36)$ & $10(48)$ & $6(29)$ & $9(41)$ & $7(32)$ & $6(26)$ & $4(18)$ & $18(27)$ & \\
\hline \multicolumn{10}{|c|}{ Duration of DM, no. (\%) } \\
\hline$<10 y$ & $10(45)$ & $10(48)$ & $8(38)$ & $7(32)$ & $10(45)$ & $8(35)$ & $7(32)$ & $23(34)$ & 0.519 \\
\hline$\geq 10 y$ & $12(55)$ & $11(52)$ & $13(62)$ & $15(68)$ & $12(55)$ & $15(65)$ & $15(68)$ & $43(64)$ & \\
\hline \multicolumn{10}{|c|}{ Hypertension, no. (\%) } \\
\hline Yes & $9(41)$ & $8(38)$ & $10(48)$ & $9(41)$ & $8(36)$ & $8(35)$ & $7(32)$ & $18(27)$ & 0.168 \\
\hline No & $13(59)$ & $13(62)$ & $11(52)$ & $13(59)$ & $14(64)$ & $15(65)$ & $15(68)$ & 49 (73) & \\
\hline \multicolumn{10}{|c|}{ Heart disease, no. (\%) } \\
\hline Yes & $9(41)$ & $7(33)$ & $1(5)$ & $3(14)$ & $4(18)$ & $2(9)$ & $2(9)$ & $14(21)$ & 0.004 \\
\hline No & $13(59)$ & $14(67)$ & $20(95)$ & $19(86)$ & $18(82)$ & $21(91)$ & $20(91)$ & $53(79)$ & \\
\hline \multicolumn{10}{|c|}{ Renal disease, no. (\%) } \\
\hline Yes & $0(0)$ & $0(0)$ & $0(0)$ & $0(0)$ & $0(0)$ & $0(0)$ & $0(0)$ & $5(7)$ & 0.002 \\
\hline No & $22(100)$ & $21(100)$ & $21(100)$ & $22(100)$ & $22(100)$ & $23(100)$ & $22(100)$ & $62(93)$ & \\
\hline \multicolumn{10}{|c|}{ Asthma, no. (\%) } \\
\hline Yes & $0(0)$ & $0(0)$ & $0(0)$ & $1(5)$ & $1(5)$ & $0(0)$ & $1(5)$ & $3(4)$ & 0.085 \\
\hline No & $22(100)$ & $21(100)$ & $21(100)$ & 21 (95) & $21(95)$ & $23(100)$ & $21(95)$ & $64(96)$ & \\
\hline \multicolumn{10}{|c|}{ Neuropathy, no. (\%) } \\
\hline Yes & 13 (59) & $14(67)$ & $11(52)$ & $17(77)$ & $14(64)$ & $18(78)$ & $16(73)$ & $42(63)$ & 0.305 \\
\hline No & $9(41)$ & $7(33)$ & $10(48)$ & $5(23)$ & $8(36)$ & $5(22)$ & $6(27)$ & $25(37)$ & \\
\hline \multicolumn{10}{|c|}{ Drug allergy, no. (\%) } \\
\hline Yes & $2(9)$ & $1(5)$ & $2(10)$ & $2(9)$ & $0(0)$ & $4(17)$ & $2(9)$ & $15(22)$ & 0.009 \\
\hline No & $20(91)$ & $20(95)$ & $19(90)$ & $20(91)$ & $22(100)$ & $19(83)$ & $20(91)$ & $52(78)$ & \\
\hline
\end{tabular}

Group $1=$ diazepam $(n=22)$, group $2=$ acetaminophen $(n=21)$, group $3=$ mefenamic acid $(n=21)$, group $4=$ diazepam and acetaminophen $(n=22)$, group $5=$ diazepam and mefenamic acid $(n=22)$, group $6=$ peribulbar anesthesia with lidocaine $(n=23)$, group $7=$ intramuscular injection of ketorolac tromethamine $(n=22)$, group $8=$ placebo $(n=67), \mathrm{DM}=$ diabetes mellitus, $\mathrm{y}=$ years.

${ }^{a}$ Chi-square test was performed to compare among groups of oral treatment group, injection group, and control group. The variables of heart disease, renal disease, and asthma were tested with Fisher's exact test due to small sample size.

diastolic pressure $(P=0.030)$. There was no significant difference in blood pressure changes between normal patients and hypertensive patients with adequate medication control (data not shown).

There were no obvious pulse changes after PRP treatment in most of the patients. Mean changes in pulse rate for all of the patients were $-1.86 \pm 6.08 / \mathrm{min}$. There were no significant changes in pulse rate after PRP treatments. Also, there was no statistical significance in pulse rate changes among each group.

None of the patients receiving oral drugs or intramuscular ketorolac tromethamine injection reported any discomfort about the medication. Three patients receiving peribulbar injection experienced transient subdermal ecchymosis. No other complications were noted after peribulbar injection. No allergic reaction was noted in any of the patients in this study.

\section{Discussion}

Our original goal was to find out a safe, noninvasive alternative to present treatment options for pain amelioration in PRP patients. Unfortunately, our results have shown that oral diazepam, acetaminophen, mefenamic acid, and intramuscular injection of ketorolac tromethamine are not effective for pain associated with 
Table 2 Parameters of laser treatments among groups

\begin{tabular}{|c|c|c|c|c|c|c|c|c|c|}
\hline & Group 1 & Group 2 & Group 3 & Group 4 & Group 5 & Group 6 & Group 7 & Group 8 & Total \\
\hline No. of patient & 22 & 21 & 21 & 22 & 22 & 23 & 22 & 67 & 210 \\
\hline Spot size $(\mu \mathrm{m})$ & 500 & 500 & 500 & 500 & 500 & 500 & 500 & 500 & 500 \\
\hline $\begin{array}{l}\text { No. of laser, } \\
\text { mean (SD) }\end{array}$ & $465.4(84.3)$ & 437.7 (115.6) & $474.4(106.7)$ & 465.3 (118.9) & $464.4(79.5)$ & $458.0(79.8)$ & $453.1(80.9)$ & 448.5 (104.7) & 450.9 (109.5) \\
\hline $\begin{array}{l}\text { Power, mean } \\
(\mathrm{SD})(\mathrm{mW})\end{array}$ & $332.4(89.2)$ & 352.3 (111.6) & $325.3(91.4)$ & $285.2(107.5)$ & $297.0(70.6)$ & 280.7 (66.9) & $248.1(45.7)^{\mathrm{a}}$ & $313.7(97.0)$ & 305.9 (92.5) \\
\hline
\end{tabular}

Group $1=$ diazepam, group $2=$ acetaminophen, group $3=$ mefenamic acid, group $4=$ diazepam and acetaminophen, group $5=$ diazepam and mefenamic acid, group $6=$ peribulbar anesthesia with lidocaine, group $7=$ intramuscular injection of ketorolac tromethamine, group $8=$ placebo, $\mathrm{SD}=$ standard deviation

aStatistical significance in Dunnett test compared with control group after ANOVA reached statistical difference.

Table 3 Pain scores and haemodynamic response by PRP patients

\begin{tabular}{lccccccccc}
\hline & Group 1 & Group 2 & Group 3 & Group 4 & Group 5 & Group 6 & Group 7 & Group 8 & Total \\
\cline { 2 - 9 } \begin{tabular}{l} 
No. of patient \\
\cline { 2 - 8 }
\end{tabular} & 22 & 21 & 21 & 22 & 22 & 23 & 22 & 67 & 210 \\
\hline $\begin{array}{l}\text { Changes in } \\
\text { systolic pressure, } \\
\text { mean (SD) }\end{array}$ & $29.6(24.6)^{\mathrm{a}}$ & $26.9(19.6)^{\mathrm{a}}$ & $30.1(20.0)^{\mathrm{a}}$ & $23.6(25.7)^{\mathrm{a}}$ & $27.4(32.1)^{\mathrm{a}}$ & $16.5(20.4)^{\mathrm{a}, \mathrm{b}}$ & $23.5(15.8)^{\mathrm{a}}$ & $27.7(23.3)^{\mathrm{a}}$ & $25.2(23.2)$ \\
$\begin{array}{l}\text { Changes in } \\
\text { diastolic pressure, } \\
\text { mean (SD) }\end{array}$ & $12.1(19.2)^{\mathrm{a}}$ & $18.1(16.7)^{\mathrm{a}}$ & $13.6(19.0)^{\mathrm{a}}$ & $10.7(19.5)^{\mathrm{a}}$ & $14.9(20.7)^{\mathrm{a}}$ & $4.8(13.3)^{\mathrm{b}}$ & $15.0(10.8)^{\mathrm{a}}$ & $15.0(13.9)^{\mathrm{a}}$ & $12.2(17.5)$ \\
$\begin{array}{l}\text { Changes in } \\
\text { pulse, mean (SD) }\end{array}$ & $0.0(6.1)$ & $-1.6(4.8)$ & $-0.1(7.2)$ & $-2.5(6.2)$ & $-0.5(4.6)$ & $-2.0(4.3)$ & $-5.3(6.9)$ & $-2.4(6.7)$ & $-1.9(6.1)$ \\
$\begin{array}{l}\text { Pain scores, } \\
\text { mean (SD) }\end{array}$ & $3.0(1.0)$ & $3.0(0.8)$ & $2.9(0.9)$ & $3.1(1.0)$ & $2.9(1.0)$ & $0.8(1.3)^{\mathrm{b}}$ & $2.6(1.0)$ & $3.0(1.0)$ & $2.7(1.2)$
\end{tabular}

Group 1 =diazepam, group $2=$ acetaminophen, group $3=$ mefenamic acid, group $4=$ diazepam and acetaminophen, group $5=$ diazepam and mefenamic acid, group $6=$ peribulbar anesthesia with lidocaine, group $7=$ intramuscular injection of ketorolac tromethamine, group $8=$ placebo, $\mathrm{SD}=$ standard deviation

${ }^{\text {a }} P$-value $<0.05$ in paired $t$ test.

b Statistical significance was found with the regression model while controlling variables of sex, age, associated systemic diseases, and parameters of laser treatments. The control group was assigned as the reference group.

PRP. Only peribulbar anaesthesia is effective in reducing pain and blood pressure rise accompanied by PRP. Our results show that PRP is a painful procedure for most patients, and such painful sensation can trigger a significant blood pressure rise. Such painful sensation cannot be relieved by anxiolytic agents, indicating that such pain is really procedure related instead of due to patients' anxiety.

Effective analgesics can prevent the stress and anxiety associated with pain. Retrobulbar anaesthesia has been proven to be an effective way of anaesthesia for various kinds of ocular surgeries. Bloom and Brucker ${ }^{19}$ suggest providing retrobulbar anaesthesia for patients with intolerable pain associated with PRP treatment. However, retrobulbar anaesthesia administration is an invasive procedure with possible vision threatening and systemic complications. , $^{8,20-31}$
Peribulbar anaesthesia is as effective as retrobulbar anaesthesia and appears to lead to fewer sight- and life-threatening complications. ${ }^{9,11,32,33}$ Subtenon anaesthesia is another alternative with fewer risks, ${ }^{10}$ but it is still an invasive treatment in patients. Transcutaneous electrical nerve stimulation has been advocated in the practice of PRP. ${ }^{12}$ It has been reported to be an effective and noninvasive measure to reduce patients' painful sensation. However, transcutaneous electrical nerve stimulation requires special instrumentation, and its optimal setting for ocular pain remains to be determined. Our results have shown that peribulbar anaesthesia is an effective painrelieving procedure during PRP. More than $90 \%$ of our patients request peribulbar anaesthesia again for subsequent laser treatment. However, some serious visual or systemic complications, such as hyphema, 
ocular perforation, choroidal neovascularization, retrobulbar haemorrhage, expulsive haemorrhage, visual loss, nosocomial meningitis, and grand mal seizure, have been reported with the use of this type of anaesthesia. ${ }^{11,32,34-38}$ Although the safety and efficacy of peribulbar anaesthesia can be enhanced by some modifications, ${ }^{39,40}$ it is still an invasive procedure.

Most patients can tolerate pain associated with PRP. Only three patients dropped out from this study due to intolerable pain; therefore, it may not be justified to perform an invasive local anesthetic procedure routinely. The risk-benefit ratio of any local anesthetic technique must be considered.

Acetaminophen is a commonly used, over-the-counter analgesic. It has been shown to be effective for a variety of pain conditions, including postoperative pain. ${ }^{41}$ Mefenamic acid belongs to the group of nonsteroidal anti-inflammatory drugs (NSAIDs). It has been proven useful for treatment of dysmenorrhea and rheumatic arthritis. ${ }^{42,43}$ Ketorolac tromethamine also belongs to the NSAID group. It has been shown to be effective for corneal abrasion ${ }^{44}$ and postoperative pain. ${ }^{45}$ The efficacy of ketorolac tromethamine has been considered to be equal to morphine in the alleviation of pain, but with less central nervous system complications. ${ }^{45}$ Diazepam is a commonly used anxiolytic agent. A previous study has shown that anxiety increases pain sensation. ${ }^{46}$ Unfortunately, diazepam or its combination with the nonopioids analgesics mentioned above failed to demonstrate the effectiveness against PRP-associated pain in our study. Of note, although our study has shown that oral or intramuscular NSAIDs are not effective for PRP-associated pain, topical NSAID has been reported to be effective in reducing PRP-induced pain. ${ }^{7}$ The difference might be related to the local drug concentration.

Pain during PRP is thought to result from photocoagulating the ciliary nerves running in the suprachoroidal space. ${ }^{19}$ As a general rule, patients experience more pain when treating the horizontal meridians. Pain can be minimized by using shorterduration and less-intense burns. A longer repetitive rate in the laser setting and the avoidance of krypton red may also help in reducing pain. ${ }^{19}$

In addition to drug administration and laser parameter adjustment, other noninvasive measures can be investigated to reduce patients' pain sensation during PRP treatment. Previous research has found that possible pain-inhibiting mechanisms that are endogenous opioid release, blood pressure reactivity, and distraction of attention; possible pain-increasing mechanisms are autonomic and muscular reactivity, misattribution of arousal, hypervigilance to pain, worrying, and avoidance behaviour. $^{46}$ Therefore, measures to promote paininhibiting mechanisms or decrease pain-increasing mechanisms may help reduce patients' painful sensation during PRP treatment. Use of some psychological interventions, such as positive emotion induction or relaxation procedures, was found useful for acute pain management. ${ }^{15}$ In addition, music has been found to be effective to ameliorate pain and suffering by distraction of attention. ${ }^{47,48}$ Further research might be warranted to explore their effectiveness in PRP treatment.

Most of our patients experienced increased blood pressure after PRP treatment. An increase in systemic blood pressure during surgery indicates haemodynamic responses to pain. Acute pain increases blood pressure by increasing sympathetic activity. ${ }^{49}$ Increasing evidence from animal and human research indicates a close relationship between pain-regulating systems and blood pressure. ${ }^{50}$ The same brain stem nuclei and the same neurotransmitters, monoamines and endorphins, are associated with both functions. ${ }^{51-56}$ Therefore, blood pressure changes can be viewed as a related evaluation of pain. On the other hand, pulse remained the same after PRP treatment in all our patients. Possible explanations for the discrepancy between blood pressure and pulse in the patients is that blood pressure responds more sensitively to pain stress than pulse, or pulse restores to baseline status more quickly than blood pressure.

Although we designed our study carefully, the study has limitations. First, the patients and the drug administrators cannot be blinded. This could be a source of bias. Second, the patients in this study were recruited from multiple surgeons. Although most of the treatment parameters are the same, there are probably some minor differences in treatment modality for each surgeon. For instance, the way in which a patient is treated when the patient complains about pain or discomfort may be different. Some surgeons may comfort patients verbally, while others may not. Whether such differing approaches affect the outcome has not been determined yet.

In conclusion, PRP is a painful treatment for most patients. This study suggests that peribulbar anaesthesia could reduce the pain of PRP. The study also suggests that the use of diazepam, acetaminophen, mefenamic acid, or intramuscular injection of ketorolac tromethamine has no effect on pain associated with PRP. Owing to the associated blood pressure rise with PRP, caution must be taken if PRP is performed in patients with untreated hypertension. To perform PRP effectively and safely, more research into other interventions to reduce the pain of PRP is needed if it is to continue as the treatment of choice for PDR. 


\section{Acknowledgements}

This study was supported by grants from National Science Council, Taiwan (NSC 93-2311-B-182A-001, NSC 93-2311-B-182A-003).

\section{References}

1 Photocoagulation treatment of proliferative diabetic retinopathy. Clinical application of Diabetic Retinopathy Study (DRS) findings, DRS Report Number 8 The Diabetic Retinopathy Study Research Group. Ophthalmology 1981; 88: 583-600.

2 Early photocoagulation for diabetic retinopathy. ETDRS report number 9 Early Treatment Diabetic Retinopathy Study Research Group. Ophthalmology 1991; 98: 766-785.

3 Proliferative diabetic retinopathy: treatment with xenon-arc photocoagulation. Interim report of multicenter randomized controlled trial. Br Med J 1977; 1: 739-741.

4 Hercules BL, Gayed II, Lucas SB, Jeacock J. Peripheral retinal ablation in the treatment of proliferative diabetic retinopathy: a three-year interim report of a randomized, controlled study using the argon laser. Br J Ophthalmol 1977; 61: $555-563$

5 Cook HL, Newsom RS, Mensah E, Saeed M, James D, Ffytche TJ. Etonox as an analgesic agent during panretinal photocoagulation. Br J Ophthalmol 2002; 86: 1107-1108.

6 Stevens JD, Foss AJ, Hamilton AM. No-needle one-quadrant sub-tenon anaesthesia for panretinal photocoagulation. Eye 1993; 7: 768-771.

7 Weinberger D, Ron Y, Lichter H, Rosenblat I, Axer-Siegel R, Yassur Y. Analgesic effect of topical sodium, diclofenac $0.1 \%$ drops during retinal laser photocoagulation. $\mathrm{Br} J$ Ophthalmol 2000; 84: 135-137.

8 Edge KR, Nicoll JM. Retrobulbar hemorrhage after 12,500 retrobulbar blocks. Anesth Analg 1993; 76: 1019-1022.

9 Ripart J, Lefrant JY, de La Coussaye JE, Prat-Pradal D, Vivien B, Eledjam JJ. Peribulbar versus retrobulbar anesthesia for ophthalmic surgery: an anatomical comparison of extraconal and intraconal injections. Anesthesiology 2001; 94: 56-62.

10 Guise PA. Sub-tenon anesthesia: a prospective study of 6,000 blocks. Anesthesiology 2003; 98: 964-968.

11 Duker JS, Belmont JB, Benson WE, Brooks Jr HL, Brown GC, Federman JL et al. Inadvertent globe perforation during retrobulbar and peribulbar anesthesia. Patient characteristics, surgical management, and visual outcome. Ophthalmology 1991; 98: 519-526.

12 Whitacre MM. The effect of transcutaneous electrical nerve stimulation on ocular pain. Ophthalmic Surg 1991; 22: 462-466.

13 Friedberg MA, Palmer RM. A new technique of local anesthesia for panretinal photocoagulation. Ophthal Surg 1991; 22: 619-621.

14 Moses KC, Norbury Jr JW. Anesthesia for retinal photocoagulation. Ophthal Surg 1990; 21: 156.

15 Bruehl S, Carlson CR, McCubbin JA. Two brief interventions for acute pain. Pain 1993; 54: 29-36.

16 Luchetti M, Magni G, Marraro G. A prospective randomized double-blinded controlled study of ropivacaine $0.75 \%$ versus bupivacaine $0.5 \%$-mepivacaine $2 \%$ for peribulbar anesthesia. Reg Anesth Pain Med 2000; 25: 195-200.
17 Melzack R. The McGill Pain Questionnaire: major properties and scoring methods. Pain 1975; 1: 277-299.

18 Jensen MP, Karoly P, O'Riordan EF, Bland Jr F, Burns RS. The subjective experience of acute pain. An assessment of the utility of 10 indices. Clin J Pain 1989; 5: 153-159.

19 Bloom SM, Brucker AJ. Laser surgery of the posterior segment. J.B. Lippincott: Philadelphia, 1991.

20 Han SK, Kim JH, Hwang JM. Persistent diplopia after retrobulbar anesthesia. J Cataract Refract Surg 2004; 30: 1248-1253.

21 Lau LI, Lin PK, Has WM, Liu JH. Ipsilateral globe penetration and transient contralateral amaurosis following retrobulbar anesthesia. Am J Ophthalmol 2003; 135: 251-252.

22 Brod RD. Transient central retinal artery occlusion and contralateral amaurosis after retrobulbar anesthetic injection. Ophthal Surg 1989; 20: 643-646.

23 Hersch M, Baer G, Dieckert JP, Lambert HM, Shore JW. Optic nerve enlargement and central retinal-artery occlusion secondary to retrobulbar anesthesia. Ann Ophthalmol 1989; 21: 195-197.

24 Jindra LF. Blindness following retrobulbar anesthesia for astigmatic keratotomy. Ophthal Surg 1989; 20: 433-435.

25 Javitt JC, Addiego R, Friedberg HL, Libonati MM, Leahy JJ. Brain stem anesthesia after retrobulbar block. Ophthalmology 1987; 94: 718-724.

26 Ahn JC, Stanley JA. Subarachnoid injection as a complication of retrobulbar anesthesia. Am J Ophthalmol 1987; 103: 225-230.

27 Cohen SM, Sousa FJ, Kelly NE, Wendel RT. Respiratory arrest and new retinal hemorrhages after retrobulbar anesthesia. Am J Ophthalmol 1992; 113: 209-211.

28 Hamed LM, Mancuso A. Inferior rectus muscle contracture syndrome after retrobulbar anesthesia. Ophthalmology 1991; 98: 1506-1512.

29 Weidenthal DT, Kind JW. Cardiopulmonary arrest after retrobulbar anesthesia in a patient with an orbital roof defect. Am J Ophthalmol 1995; 120: 535-536.

30 Blodi BA, Williams CA. Purscher-like retinopathy after uncomplicated administration of retrobulbar anesthesia. Am J Ophthalmol 1997; 124: 702-703.

31 Devoto MH, Kersten RC, Zalta AH, Kulwin DR. Optic nerve injury after retrobulbar anesthesia. Arch Ophthalmol 1997; 115: 687-688.

32 Davis II DB, Mandel MR. Efficacy and complication rate of 16,224 consecutive peribulbar blocks. A prospective multicenter study. J Cataract Refract Surg 1994; 20: 327-337.

33 Demediuk OM, Dhaliwal RS, Papworth DP, Devenyi RG, Wong DT. A comparison of peribulbar and retrobulbar anesthesia for vitreoretinal surgical procedures. Arch Ophthalmol 1994; 113: 908-913.

34 Belfort Jr R, Muccioli C. Hyphema after peribulbar anesthesia for cataract surgery in Fuchs' heterochromic iridocyclitis. Ocul Immunol Inflamm 1998; 6: 57-58.

35 Peronnet D, Kisterman JP. Nosocomial meningitis after peribulbar anesthesia. J Clin Anesth 1997; 9: 675.

36 Puustjarvi T, Purhonen S. Permanent blindness following retrobulbar hemorrhage after peribulbar anesthesia for cataract surgery. Ophthal Surg 1992; 23: 450-452.

37 Cadera W. Diplopia after peribulbar anesthesia for cataract surgery. J Pediatr Ophthalmol Strab 1998; 35: 240-241.

38 Wang NK, Wu WC, Chuang LH, Tsao YP, Chen TL, Lai CC. Choroidal neovascularization after globe penetration by peribulbar anesthesia. Arch Ophthalmol 2004; 122: 1544-1546. 
39 Fathi AA, Soliman MM. Carticaine versus lidocaine for peribulbar anesthesia in cataract surgery. J Cataract Refract Surg 2002; 28: 513-516.

40 Kuhn F, Mester V, Berta A. The continuous-injection technique to reduce complications during retrobulbar anesthesia. Ophthal Surg Lasers 1999; 30: 67-68.

41 Moore A, Collins S, Carroll D, McQuay H. Paracetamol with and without codeine in acute pain: a quantitative systematic review. Pain 1997; 70: 193-201.

42 Simon LS, Mills JA. Nonsteroidal antiinflammatory drugs (second of two parts). N Engl J Med 1980; 302: 1237-1243.

43 Duncan KM, Hart LL. Nonsteroidal antiinflammatory drugs in menorrhagia. Ann Pharmacother 1993; 27: 1353-1355.

44 Weaver CS, Terrell KM. Evidence-based emergency medicine: update: do ophthalmic nonsteroidal antiinflammatory drugs reduce the pain associated with simple corneal abrasion without delaying healing? Ann Emerg Med 2003; 41: 134-140.

45 Anthony D, Jasinski DM. Postoperative pain management: morphine versus ketorolac. J Perianesth Nurs 2002; 17: 30-42.

46 Janssen SA. Negative affect and sensitization to pain. Scand J Psych 2002; 43: 131-137.

47 Chan YM, Lee PW, Ng TY, Ngan HY, Wong LC. The use of music to reduce anxiety for patients undergoing colposcopy: a randomized trial. Gynecol Oncol 2003; 91: 213-217.
48 Koch ME, Kain ZN, Ayoub C, Rosenbaum SH. The sedative and analgesic sparing effect of music. Anesthesiology 1998; 89: 300-306.

49 Chawla PS, Kochar MS. Effect of pain and nonsteroidal analgesics on blood pressure. Wis Med J 1999; 98: 22-29.

50 Schobel HP, Ringkamp M, Behrmann A, Forster C, Schmieder RE, Handwerker HO. Hemodynamic and sympathetic nerve responses to painful stimuli in normotensive and borderline hypertensive subjects. Pain 1996; 66: 117-124.

51 Buscher HH, Hill RC, Romer D, Cardinaux F, Closse A, Hauser D et al. Evidence for analgesic activity of enkephalin in the mouse. Nature 1976; 261: 423-425.

52 Florez J, Mediavilla A. Respiratory and cardiovascular effect of met-enkephalin applied to the ventral surface of the brain stem. Brain Res 1977; 138: 585-900.

53 Lemaire I, Tseng R, Lemaire S. Systemic administration of beta-endorphin potent hypotensive effect involving a serotonergic pathway. Proc Natl Acad Sci USA 1978; 75: 6240-6242.

54 Akil H, Liebeskind JC. Monoaminergic mechanisms of stimulation-produced analgesia. Brain Res 1975; 94: 279-296.

55 Chalmers JP. Brain amines and models of experimental hypertension. Circ Res 1975; 36: 469-480.

56 Scriabine A, Clineschmidt BV, Sweet CS. Central noradrenergic control of blood pressure. Annu Rev Pharmacol Toxicol 1976; 16: 113-123. 